\title{
A prospective evaluation of a largely cementless total knee arthroplasty cohort without patellar resurfacing: 10-year outcomes and survivorship
}

Richard J. Napier ${ }^{1 *}$, Christopher O'Neill', Seamus O'Brien', Emer Doran', Brian Mockford', Jens Boldt² and David E. Beverland ${ }^{1}$

\begin{abstract}
Background: The theoretical benefits of a mobile bearing design in Total Knee Arthroplasty (TKA) include increased articular surface conformity with a reduction in both polyethylene wear and implant interface shear. However, to date these theoretical advantages have not been translated into published evidence of superior survivorship. This paper presents the results of a prospective, non-comparative study evaluating the performance of the mobile bearing Low Contact Stress LCS Complete Rotating Platform TKA in a largely cementless cohort without patellar resurfacing.

Methods: 237 consecutive patients (240 knees) undergoing primary TKA were prospectively recruited. All received the LCS Complete Rotating Platform TKA (DePuy International, Leeds, UK). Clinical and radiographic assessments were performed at 3, 12, 60 and 120 months post-operatively. Radiographic evaluation was performed by an independent external surgeon.

Results: The mean age was 70.3 years. $77.5 \%$ of cases were cementless. Radiographic assessment suggested excellent femoral component fixation. 22 tibial radiolucent lines (RLLs) $>1 \mathrm{~mm}$ were observed in $12 \mathrm{knees}$. No RLLs were progressive. There have been two revisions; one for late infection and one for aseptic loosening. No patients underwent secondary patellar resurfacing. The cumulative implant survivorship, using component revision for any reason as the endpoint, was $98.9 \%(95 \% \mathrm{Cl}, 95.6$ to $99.7 \%)$ at 10 years.
\end{abstract}

Conclusions: The excellent survivorship at a minimum 10-year follow-up supports the use of uncemented porous coated fixation without patellar resurfacing with the non-posterior stabilized LCS Complete Rotating Platform TKA.

Keywords: Cementless TKA, LCS total knee, Cementless knee survivorship, Knee replacement

\section{Background}

The theoretical benefits of a rotating platform design in Total Knee Arthroplasty (TKA) are well-documented $[1,2]$. The concept of increasing the congruity of the articular surface to reduce polyethylene wear rates, coupled with the use of a mobile bearing (MB) to minimize constraint forces associated with mechanical loosening should theoretically be associated with greater long-term survivorship [3]. However to date

\footnotetext{
*Correspondence: rjnapier@doctors.org.uk

'Orthopaedic Outcomes Assessment Unit, Musgrave Park Hospital,

Stockman's Lane, Belfast BT9 7JB, Northern Ireland

Full list of author information is available at the end of the article
}

such advantages have not been demonstrated in the literature [4-9].

Although cemented fixation for TKA is supported within the literature as offering excellent long-term survivorship [10], cementless fixation has many benefits including shorter surgical time, which may reduce infection rates [11], preservation of bone stock for revision procedures [12], and prevention of third body cement wear. The most common cause of late failure in TKA remains aseptic loosening particularly the tibial component [13-16]. A recent Cochrane review suggested if good early fixation is achieved the potential for later

(c) The Author(s). 2018 Open Access This article is distributed under the terms of the Creative Commons Attribution 4.0 International License (http://creativecommons.org/licenses/by/4.0/) which permits unrestricted use, distribution, and reproduction in any medium, provided you give appropriate credit to the original author(s) and the source, provide a link to the Creative Commons license, and indicate if changes were made. The Creative Commons Public Domain Dedication waiver (http://creativecommons.org/publicdomain/zero/1.0/) applies to the data made available in this article, unless otherwise stated. 
aseptic loosening is reduced by up to half compared to cemented TKA [17].

Patellar resurfacing also creates significant debate among knee surgeons with numerous studies both for [18-21] and against $[22,23]$. Due to the wide variety of trochlear geometry between TKA designs, it may be more appropriate to refer to specific designs when debating patellar resurfacing [24-26]. Additional factors such as surgical technique and the primary indication for knee arthroplasty also contribute to reducing anterior knee pain post-operatively $[27,28]$. This prospective, non-comparative study aimed to evaluating the performance of a rotating platform TKA using predominantly cementless fixation and without patellar resurfacing at a minimum 10-year follow-up.

\section{Methods}

Between March 2002-January 2003, 237 consecutive patients (240 knees) scheduled for primary TKA at a regional orthopaedic centre were prospectively recruited. Exclusion criteria included: previous knee surgery (except for open or arthroscopic meniscectomy) and/or an inability to give informed consent. Institutional Review Board (IRB) approval was obtained from the regional research and ethics committee. (Study reference ORECNI-335-01) and written consent was obtained from all patients.

All patients received a LCS Complete Rotating Platform TKA (DePuy International, Leeds, UK), without patellar resurfacing. Surgery was performed under the care of the senior author. The philosophy for alignment was to achieve a balanced knee through bone cuts rather than soft tissue releases, and not to aim for a neutral mechanical axis [29, 30]. At the beginning of the study hybrid fixation with a cemented tibia was used in female patients with valgus deformities due to concern regarding early post-operative tibial insufficiency fractures [31]. Prophylactic antibiotics were administered prior to tourniquet inflation, with the tourniquet being released after deep closure. A medial Insall approach was utilized in all cases. The patella underwent removal of rim osteophytes, with a lateral patellar release only performed in cases were persistent patellar tilt or a mal-tracking was observed. In more severe cases (Sperner grade IV) a lateral facetectomy was performed [Fig. 1] [32]. No patellae underwent resurfacing. Thirty knees underwent lateral release and 1 required facetectomy.

All knees were closed in flexion and kept flexed on a pillow for $6 \mathrm{~h}$ to reduce blood loss [33]. Patients without a personal history of venous thromboembolism received oral aspirin $150 \mathrm{mg}$ once daily for 6 weeks as thromboprophylaxis [34, 35]. Anesthesia consisted of a spinal anesthetic combined with regional femoral and sciatic nerve blocks. All patients were mobilized full weightbearing on the first post-operative day.

Patients were reviewed by Arthroplasty Care Practitioners [36] with clinical and radiographic assessments at 3,12, 60 and 120 months post-operatively.

Clinical outcome was assessed by comparison of pre and postoperative Oxford Knee Scores (OKS), American Knee Society Scores (AKSS) and Bartlett Patellar Scores (BPS). Quality of life was assessed using the 12 item Short Form Health Survey (SF-12).

Radiographic evaluation was performed by an independent external surgeon. Standardised erect anteroposterior (AP), lateral and skyline patellar views were obtained. Radiographs were assessed for the presence of radiolucent lines (RLLs) and osteolytic defects. A RLL was defined as a radiolucency of $\geq 1 \mathrm{~mm}$ in greater than $50 \%$ of a zone. The zones are illustrated in Fig. 2.

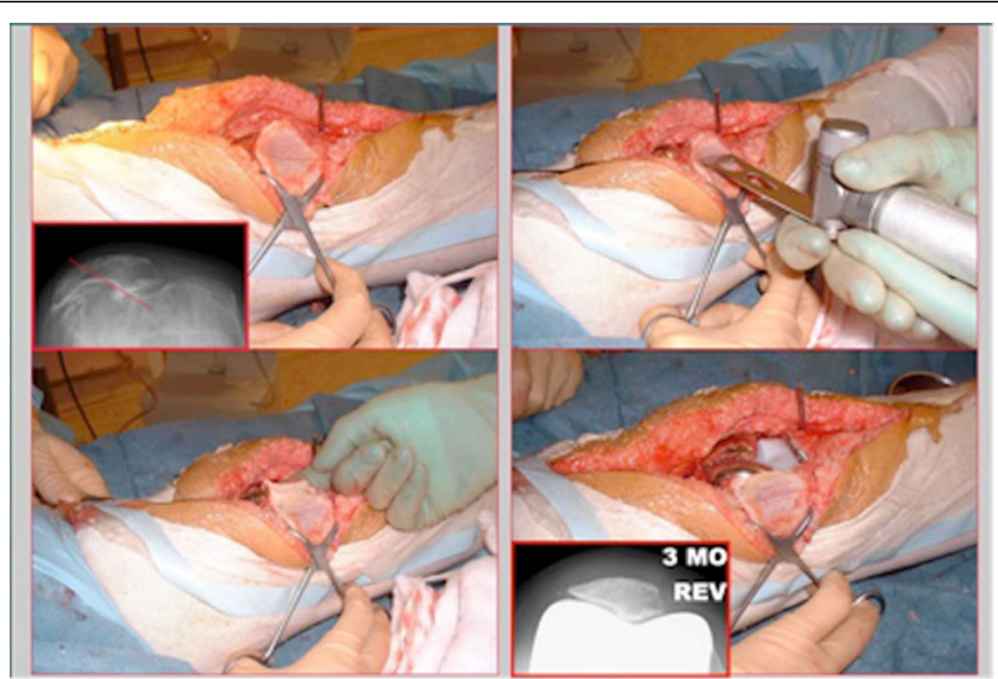

Fig. 1 Demonstrating the technique for patellar contouring with an inset showing preoperative and three-month skyline views 
Revision for any reason was used as the end point for survivorship. Of the 237 patients enrolled in the study, 84 subjects were withdrawn at the end of 10 years: 70 Deceased, 2 Revisions, 12 lost to follow-up (7 due to ill-health, 3 moved away and 2 untraceable).

\section{Statistical analysis}

Survivorship was determined using the Kaplan-Meier method. Subjects who died or were lost to follow-up were included in the survivorship analysis and in the calculation of the $95 \%$ confidence intervals.

\section{Results}

The mean age of the patients at the time of surgery was 70.3 years (range 39-89). The series included 91 males and 146 females. One female and two males had bilateral staged knee replacements. Osteoarthritis was the indication for surgery in $94 \%$ of cases (226 knees). Other indications included inflammatory arthropathy 4.6\% (11 knees) and post-traumatic arthritis $0.4 \%$ ( 1 knee). Four knees within this study underwent TKA for isolated patellofemoral disease [28]. Patient demographics are summarised in Table 1.

Pre-operative radiological alignment was predominantly varus with 165 (68.75\%) knees being in varus alignment (Mean Hip Knee Ankle angle 10.2 ${ }^{\circ}$ ) and 75 $(31.25 \%)$ knees in valgus (Mean $\left.7.9^{\circ}\right)$. (Range $24^{\circ}$ varus $38^{\circ}$ valgus).

Of the 240 knees in the study 186 (77.5\%) were cementless, $53(22.0 \%)$ were hybrid fixation with a cemented tibial component, and $1(0.4 \%)$ was an all cemented knee. $81 \%$ of the patients were overweight or obese (Mean BMI $28.8 \mathrm{~kg} / \mathrm{m}^{2}$ ). Of the 54 cemented tibias, 53 were female and of those 49 had either a neutral or valgus preoperative alignment. A cemented component was used in the one male patient because a cementless component was unavailable.

\section{Baseline \& 10-year outcome measures}

When comparing validated outcome scores from pre-operatively to those at 10 -year review, a clinically and statistically significant improvement in all outcome measures was observed. Importantly this included patellar scores and pain scores (Table 2).

\section{Radiographic analysis}

Standardised post-operative AP and lateral radiographs were analysed using a modified Knee Society TKA Roentgenographic scoring system to determine the presence, width and location of any RLLs [37]. The AP radiograph was taken in approximately seven degrees of flexion to account for tibial resection slope and to ensure a proper view of the tibial-bone interface. The diagram in Fig. 2 shows the modified scoring system with femoral (1-4) and tibial (5-10) zones. Radiographic assessment showed no RLLs in femoral zones (1-4), suggesting excellent femoral component fixation.

Twenty-two tibial RLLs were observed in 12 subjects (12 knees) (see Table 3). Only one cemented tibial component had RLLs observed during the follow-up period $(1 / 54(1.9 \%))$. The total number of cementless tibial components with RLLs observed was 11/186 (5.9\%), with RLLs being reported twice in one patient at two different time points and in different zones. The most common locations for RLLs were Zones 5 and 7 of the proximal tibia. No RLLs were progressive.

Two knees with documented RLLs at 3 months post-operatively showed full resolution at 1, 5 and 10 -year review. Five knees had RLLs present for the first time at 1 -year, and only 1 had RLLs visible at subsequent
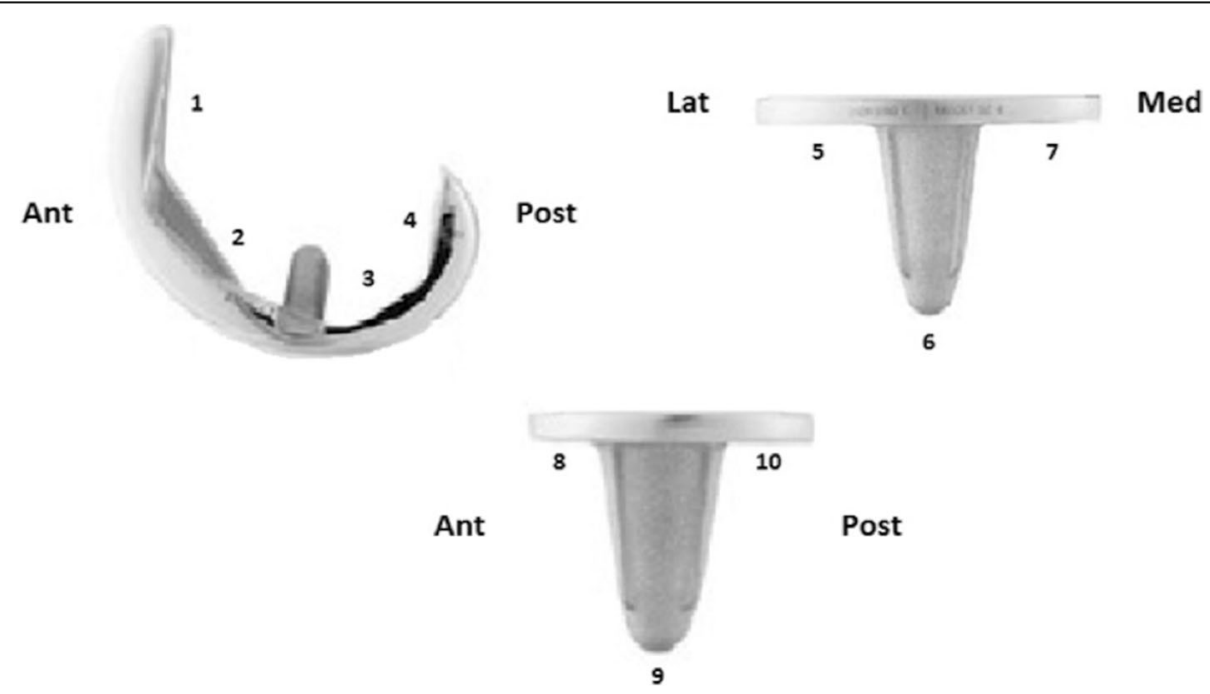

Fig. 2 Modified scoring system with femoral (1-4) and tibial (5-10) zones 
Table 1 Demographics of Enrolled Patients

\begin{tabular}{|c|c|}
\hline Patients/Knee (n) & $237 / / 240$ \\
\hline \multicolumn{2}{|l|}{ Gender (Patients (\%) } \\
\hline Male & 91 (38.4\%) \\
\hline Female & $146(61.6 \%)$ \\
\hline \multicolumn{2}{|l|}{ Age at operations (years) } \\
\hline Mean (years) & 70.3 \\
\hline Minimum (years) & 39 \\
\hline Maximum (years) & 89 \\
\hline \multicolumn{2}{|l|}{ Age groups (knees) (\%) } \\
\hline$<50$ years & $7(3 \%)$ \\
\hline $50-69$ years & $94(39 \%)$ \\
\hline $70-79$ years & $110(46 \%)$ \\
\hline $80-89$ years & $29(12 \%)$ \\
\hline \multicolumn{2}{|l|}{ Body Mass Index $\left(\mathrm{kg} / \mathrm{m}^{2}\right)$} \\
\hline Mean & 28.8 \\
\hline Minimum & 18 \\
\hline Maximum & 45 \\
\hline \multicolumn{2}{|l|}{ BMl groups $\left(\mathrm{kg} / \mathrm{m}^{2}\right)$} \\
\hline Underweight (< 18.5) & $1(0.5 \%)$ \\
\hline Normal (18.5-24.9) & 45 (19\%) \\
\hline Overweight (25.0-29.9) & 103 (43\%) \\
\hline Obese class 1(30.0-34.9) & $71(29.5 \%)$ \\
\hline Obese class 2 (35-39.9) & $17(7 \%)$ \\
\hline Morbidly obese $\geq 40$ & $3(1 \%)$ \\
\hline \multicolumn{2}{|l|}{ Primary Diagnosis } \\
\hline Osteoarthritis & $226(94.2 \%)$ \\
\hline Post traumatic Arthritis & $1(0.4 \%)$ \\
\hline Rheumatoid Arthritis & $11(4.6 \%)$ \\
\hline Other & $2(0.8 \%)$ \\
\hline
\end{tabular}

5 or 10-year review and this occurred in a different location (Zone 10). Three knees had RLLs present for the first time at 5-year review, which were no longer apparent at 10-year review. Three knees had RLLs present for first time at 10 -year review. There was no statistically significant difference in pain scores between cases with and without RLLs, (approximate t-test $p$-value of 0.77 ), suggesting neither pain nor revision was related to the presence of RLLs. Comparing RLL in cemented vs uncemented cases showed no statistical significance (Fisher's exact $p$-value $=0.308$ ).

\section{Patellofemoral alignment}

Pre- and post-operative patellofemoral alignment was measured on Merchant skyline radiographs. Pre-operatively, the patella was centrally aligned in $61.9 \%$, laterally aligned in $26.4 \%$, and medially aligned in $11.7 \%$ of patients. At initial postoperative 3 month and final review (120 months) 99.5 and $98.9 \%$ of patellae respectively showed central patellar alignment. Patellar tilt was also evaluated on pre- and postoperative skyline radiographs. Preoperatively, $31.6 \%$ of patellae lay centrally (neutral tilt), $48.0 \%$ had lateral tilt and $20.4 \%$ had medial tilt. At the 3-month post-operative review 98.0\% had neutral tilt. At 10-year follow-up, all reviewed knees exhibited neutral patellar tilt.

In this study, patients receiving cemented and uncemented tibial components were unmatched cohorts. There was no significant difference in Knee Society Pain Subscore or Knee Society Function Score between cemented and non-cemented knees at 10 years however there were fewer RLLs in the cemented tibial cohort.

Of the 240 knees in the study only 2 cementless implants underwent revision. The first case was a revision for late haematogenous infection at 9.2 years post primary surgery. The second case was for aseptic loosening at 8.3 years after primary surgery. X-rays showed anterior femoral cortical scalloping with osteolysis in femoral zones 1 and 4 , and tibial zones 5 and 8 . Intra-operatively, the femoral component was loose and only the tibial cone remained well fixed, both components were revised. Interestingly this patient had no RLLs at the time of 5-year review and was revised prior to 10-year review (Figs. 3 and 4). Ten additional patients had further surgery. Nine were early washouts without bearing exchange ( 6 for infection and 3 for non-infected haematoma) and the tenth was a late (109 months) periprosthetic fracture following a road traffic collision requiring internal fixation. There were no manipulations under anaesthetic, no cases of bearing spinout and no secondary patellar resurfacings [38].

\section{Kaplan-Meier survivorship}

The cumulative implant survivorship of the whole series using component revision for any reason as the endpoint was $98.9 \%$ (95\% CI, 95.6 to 99.7\%) at 10 years (Fig. 5). With revision due to infection excluded, cumulative implant survivorship increased to $99.4 \%$ (95\% CI 96.1 to 99.9\%) at 10 years.

\section{Discussion}

This paper encompasses three controversial issues within TKA. Firstly, the reported cohort is largely cementless; secondly all were non-posterior stabilized mobile-bearings and thirdly the patella was never resurfaced. The survivorship of this cohort is excellent.

Cementless fixation has the benefits of bone stock preservation, prevention of third body cement wear, and shorter surgical times. $[11,12]$ However the registry evidence in favour of cemented as opposed to cementless TKA is compelling, with the UK, Swedish, Australian and New Zealand registries all showing superior survivorship with cemented TKA [39-42]. In the 2014 UK 
Table 2 Summary of baseline and last review outcome measures

\begin{tabular}{lllll}
\hline Outcome Measure & Mean Score at Baseline & Mean Score at Final Review (10 years) & Change from Baseline & $p$-value \\
\hline Total Knee Score & 20.9 & 91.0 & 67.21 & 24.93 \\
Knee Function Scores & 37.7 & 64.8 & 15.16 & $<0.0001$ \\
Patella Score & 9.6 & 25.3 & 24.55 & $<.0001$ \\
Oxford Knee Score & 10.8 & 35.7 & 8.53 & $<.0001$ \\
SF-12 Physical Component & 26.9 & 36.1 & 6.98 & $<0.0001$ \\
SF-12 Mental Component & 42.4 & 50.0 & 43.20 & $<0.0001$ \\
Knee Pain Sub Score & 2.8 & 46.1 & 3.67 & $<.0001$ \\
Range of Movement (Active) & 101.4 & 105.9 & 0.0001 \\
\hline
\end{tabular}

(Note- Mean baseline score subtracted from mean final review score does not equal change from baseline due to the reduction in numbers secondary to loss to follow-up at 10-years)

National Joint Registry (NJR) report [39] cementless use fell to $2.5 \%$ compared to $6.7 \%$ in 2003 . Paradoxically in many areas of the world this minimal use of cementless TKA is in stark contrast to that of cementless total hip arthroplasty even though registry data also favours cement for that joint in terms of survivorship [39, 43] and the implants are more expensive.

Level I evidence in favour of cemented TKA is unconvincing. The prospective RCT by Park and Kim [44] has been used in support of cemented TKA [8]. Park and Kim's study [44] reported on 50 patients (100 knees) who had undergone bilateral, simultaneous cruciate retaining knee replacements with one cemented and the other cementless. At a minimum follow-up of 13 years, survival of the femoral components was $100 \%$ in both groups and there was one revision for aseptic loosening of a cementless tibial component that had occurred at 1 year. No osteolysis was identified in either group. Baker et al. [45] in their prospective RCT reported no difference in the survivorship of cemented versus uncemented cruciate retaining knees at a mean follow-up of 9 years. However, cemented TKA demonstrated higher failure rates in younger, heavier men [45]. Our study population had an average BMI of 28.8, but a decade later the average BMI for patients presenting for TKA has risen to 31.8.

A meta-analysis by Gandhi et al. [10] suggested an improved survivorship of cemented as compared to uncemented implants when they looked at 15 studies selected from a total of 1292 . Unfortunately, of the 15 studies only 5 were RCTs, with the other 10 being observational. Subgroup analysis of the 5 RCTs showed no survival difference. The authors noted that the patients in the cementless observational studies tended to be younger. In the absence of a clear advantage for either method of fixation the authors concluded that cement offered an economic advantage because of the reduced cost.

For both cemented and uncemented TKAs, aseptic loosening of the tibia is the most common reason for failure [14-16]. Although cement does have advantages

Table 3 Tibial RLL Zones identified during variable review periods

\begin{tabular}{|c|c|c|c|c|c|c|c|c|}
\hline \multirow{2}{*}{$\begin{array}{l}\text { Subject } \\
\#\end{array}$} & \multirow{2}{*}{$\begin{array}{l}\text { Cemented/ } \\
\text { Non- } \\
\text { Cemented }\end{array}$} & \multirow{2}{*}{$\begin{array}{l}\text { Follow-up } \\
\text { Interval }\end{array}$} & \multicolumn{6}{|c|}{ Tibial Radiolucencies (mm) } \\
\hline & & & Zone 5 & Zone 6 & Zone 7 & Zone 8 & Zone 9 & Zone 10 \\
\hline $1-026$ & Non-cemented & 5 years & 4 & & & & & \\
\hline $1-031$ & Non-cemented & 3 months & & & 1 & & & \\
\hline $1-053$ & Non-cemented & 5 years & & & & & 1 & \\
\hline $1-065$ & Non-cemented & 12 months & & & 1 & 1 & & \\
\hline $1-075$ & Non-cemented & 5 years & & & & & 1 & \\
\hline $1-157$ & Non-cemented & 12 months & 1 & & 1 & 1 & & \\
\hline $1-175$ & Non-cemented & 10 years & & 1 & & & & \\
\hline $1-186$ & Cemented & 10 years & & & & & 1 & \\
\hline $1-215^{*}$ & Non-cemented & 12 months & 1 & & 1 & & & \\
\hline $1-215^{*}$ & Non-cemented & 10 years & & & & & 1 & \\
\hline $1-228$ & Non-cemented & 3 months & 1 & & 1 & & & 1 \\
\hline $1-232$ & Non-cemented & 12 months & 1 & & & 1 & & \\
\hline $1-241$ & Non-cemented & 12 months & 1 & & 1 & 1 & & \\
\hline
\end{tabular}




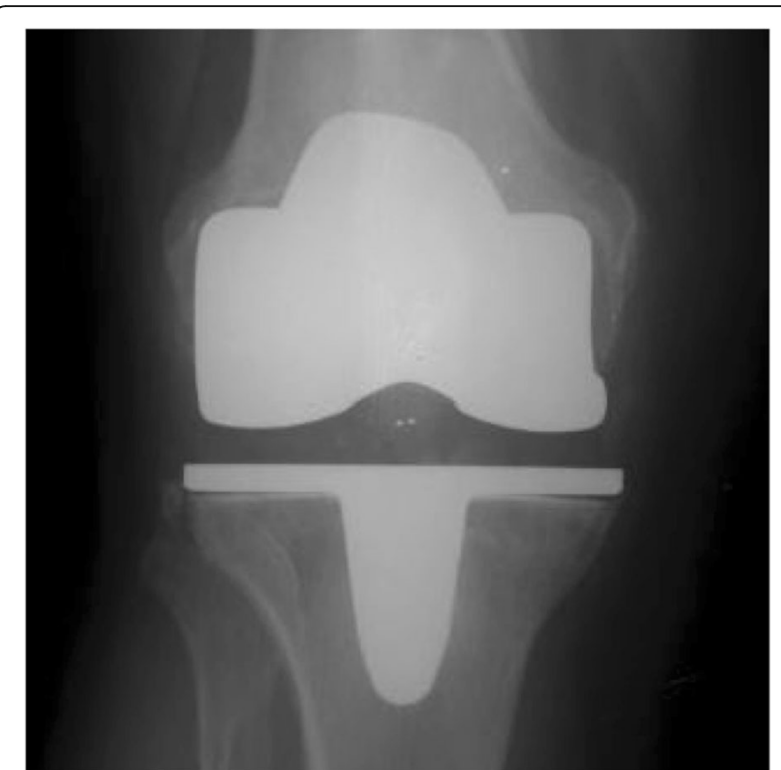

Fig. 3 Example of RLLs in Zones 5 \& 7

such as augmenting bony defects or inaccurate bone cuts [46] its weakness and mode of failure is susceptibility to torsional and shear forces [47]. Posterior stabilized designs have higher stresses which hypothetically should impact on survivorship. This hypothesis is supported by results from the 2014 UK NJR [39] where cemented cruciate retaining TKAs have a better survivorship than posterior stabilized. Similarly for cementless fixed bearing (FB) TKAs these torsional and shear stresses could result in aseptic loosening if micromotion is present during early osteointegration [11]. Hypothetically if uncemented implants can survive these early threats to

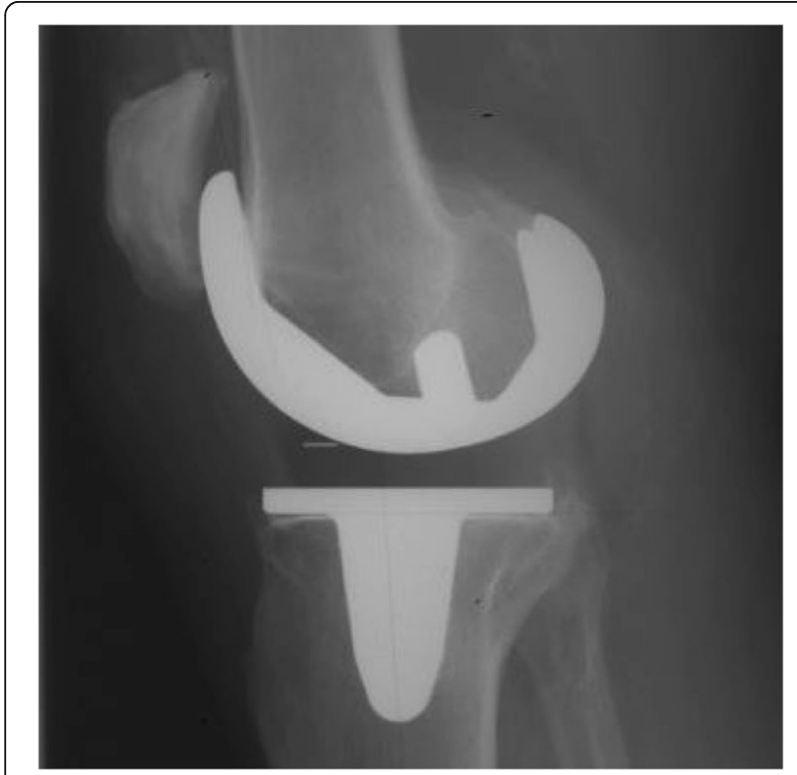

Fig. 4 Example of RLLs in Zone 8 osteointegration by forming a biological bond between bone and prosthesis this could improve long-term survivorship. This hypothesis is supported by a Cochrane review [17], however good results have been reported even with a posterior stabilized cementless TKA [47].

In contrast to the FB TKA the MB, as well as providing low contact stress and low wear [48], also reduces the stresses applied to the implant-bone interface. [3] This should reduce wear induced osteolysis and tibial loosening however these theoretical advantages over FB TKAs have not been confirmed in the literature [4-9] even though MB TKA has shown excellent medium to long-term results in function and survivorship [49, 50].

The reduced shear stress at the implant bone interface in cementless MB TKA should facilitate early osteointegration and may contribute to the survivorship in this study. One manifestation of failure of bony ingrowth is fibrous ingrowth presenting as a progressive RLL. A recognised concern with cementless porous coated tibial trays is the appearance and interpretation of RLLs. In a patient with unexplained pain this can lead to inappropriate revision. Two types of RLL have been described, physiological or pathological [51]. Physiological lines are usually $<2 \mathrm{~mm}$ with a sclerotic margin, and pathological lines are thicker, with a poorly defined border, and are usually progressive [52]. In this series only $1 / 54$ cemented tibial components exhibited RLLs compared with $12 / 186$ of the cementless tibias. Similar lines have undoubtedly resulted in unnecessary revision. We believe lines $<1 \mathrm{~mm}$ represent non-pathological fibro-osseous integration which is stable and non-progressive.

Paradoxically the cemented Oxford Uni-compartmental MB knee also suffers from inappropriate revisions due to the presence of lines below the tibial tray [53], but these are infrequent with the cementless HA coated version of the tibial tray [54].

The requirement for patellar resurfacing remains contentious and contradictory [19, 21, 23]. The geometry of the different femoral components observed between knee systems may play a role in this inconsistency [19-22]. In both resurfaced and non-resurfaced patellae, contact stresses within the trochlear sulcus are dictated by the component design [24]. With posterior stabilized designs traditionally having more patellofemoral problems [55]. The LCS system exhibits a common radius of curvature similar to that found in the native knee which allows it to accommodate the unresurfaced patella favorably [56]. However, the posterior stabilized LCS Complete was removed from the Australian market following higher than expected revision when the patella was not resurfaced [57]. With the benefits of patellar resurfacing unresolved within the literature, it is important to consider the associated risks of patellar fracture, avascular necrosis, implant loosening and instability 


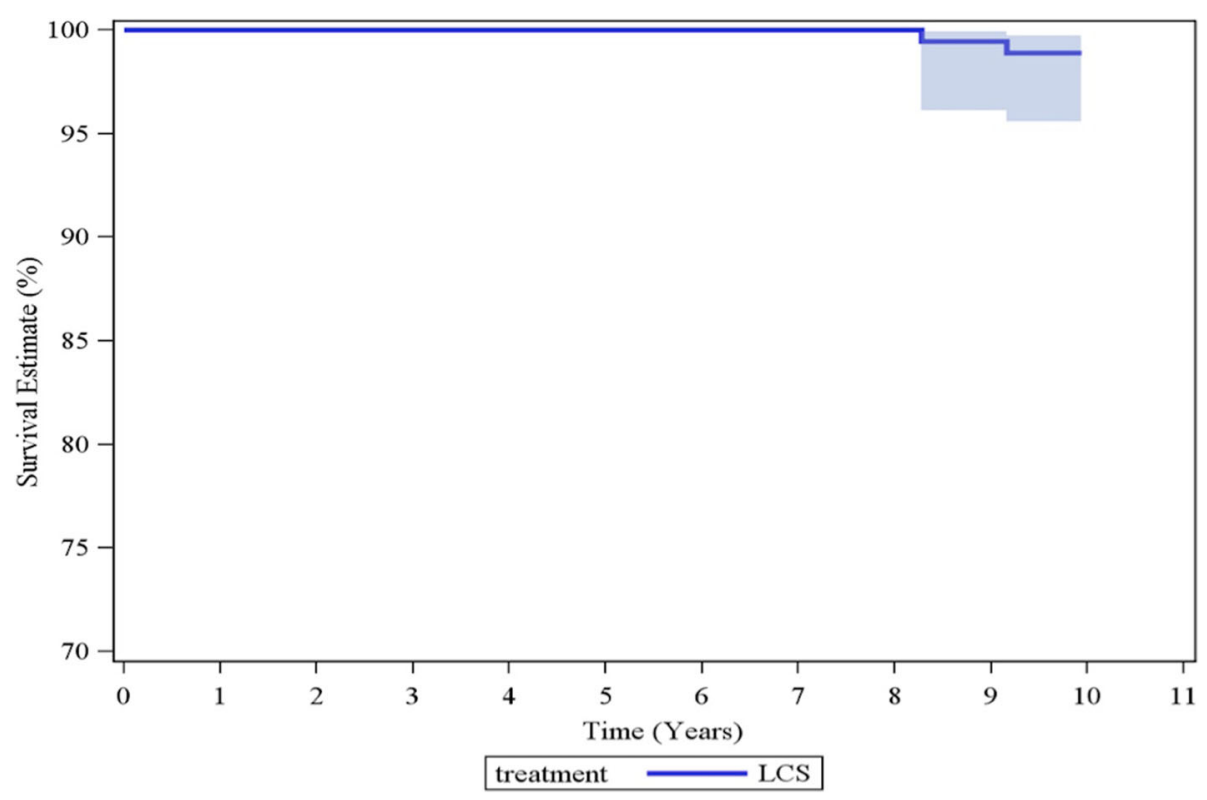

Fig. 5 Survival estimate at 10 years in 98.9\% (95\% Confidence Interval: 95.6-99.7\%)

[27]. Intraoperatively, and irrespective of implant choice or decision to resurface, it is critical to achieve central patellofemoral tracking. Persistent anterior knee pain after TKA is common with and without patellar resurfacing $[58,59]$ and secondary resurfacing can be of questionable clinical value $[18,60]$.

Weaknesses of this study include the use of a number of cemented tibial components. Recruitment for this study had been on consecutive patients and the senior author's practice at the commencement of the study was to use hybrid fixation with a cemented tibia in females with valgus deformities due to perceived concerns about tibial insufficiency fractures [31]. Since the conclusion of this study, this practice has changed, with uncemented tibial components being implanted in all cases irrespective of age, gender, or deformity. We previously reported a series of 275 consecutive valgus knees with a pre-operative deformity of $\geq 10^{\circ}$ which was completed after this study. Eighty three percent were female and of those $70 \%$ were cementless. At between 5.8 and 10.5 years follow-up, there has been only one revision, which was in a cemented tibia [31]. A further limitation was patients lost to follow-up being high. There were 84 subjects who had withdrawn from the study at the end of 10 -years, $83 \%$ of these were deceased.

\section{Conclusion}

In terms of survivorship this study supports the use of non-cemented porous coated fixation without patellar resurfacing using a non-posterior stabilized mobile bearing TKA. It exhibits excellent survivorship at a minimum 10-year follow-up with the expectation that longer-term follow-up may be superior to cemented TKA. We believe lines $<1 \mathrm{~mm}$ represent non-pathological fibro-osseous integration which is stable and non-progressive. In the absence of definitive level-1 evidence the only clear advantage for cemented TKA is cost.

\section{Abbreviations}

AKSS: American Knee Society Scores; AP: Antero-posterior; BPS: Bartlett Patellar Scores; FB: Fixed Bearing; IRB : Institutional Review Board; MB: Mobile bearing; NJR: National Joint Registry; OKS: Oxford knee scores;

RLLs: Radiolucent lines; SF-12 : 12 item Short Form Health Survey; TKA: Total Knee Arthroplasty

\section{Availability of data and materials}

The datasets used and/or analysed during the current study are available from the corresponding author on reasonable request

\section{Authors' contributions}

RJ Napier (Manuscript preparation/ Literature review/Radiographic Analysis). CO'N (Manuscript preparation/ Radiographic Analysis). SO'B (Data collection, patient assessment at follow-up). ED (Data collection, patient assessment at follow-up). BM (Data collection, patient assessment at follow-up). J B (Radiographic Analysis). DEB (Study design and implimentation, Manuscript preparation). All authors have read and approved this manuscript.

\section{Ethics approval and consent to participate}

Institutional Review Board (IRB) approval was obtained in writing from the Office for Research Ethics Committees Northern Ireland (ORECNI). (Study reference ORECNI-335-01). Written consent was obtained from all study patients.

Consent for publication

Not applicable

\section{Competing interests}

The authors declare that they have no competing interests.

\section{Publisher's Note}

Springer Nature remains neutral with regard to jurisdictional claims in published maps and institutional affiliations. 


\section{Author details}

Orthopaedic Outcomes Assessment Unit, Musgrave Park Hospital, Stockman's Lane, Belfast BT9 7JB, Northern Ireland. Akutklinik Siloah, Worbstrasse 324, CH 3073 Guemligen, Switzerland.

\section{Received: 28 December 2017 Accepted: 10 June 2018}

\section{Published online: 26 June 2018}

\section{References}

1. Goodfellow JW, O'Connor J. The mechanics of the knee and prosthesis design. J Bone Joint Surg (Br). 1978;60B(3):358-68.

2. Buechel FF, Pappas MJ. The New Jersey low contact stress knee replacement system: biomechanical rationale and review of the first 123 cemented cases. Arch Orthop and Traumatic Surg. 1986;105:197-204.

3. Callaghan JJ, Insall JN, Greenwald AS, Dennis DA, Komistek RD, Murray DW, Bourne RB, Rorabeck CH, Dorr LD. Mobile-bearing knee replacementconcept and results. J Bone Joint Surg Am. 2000;82(7):1020.

4. Aglietti P, Baldini A, Buzzi R, Lup D, De Luca L. Comparison of mobilebearing and fixed-bearing total knee arthroplasty: a prospective randomized study. J Arthroplasty. 2005;20(2):145-53.

5. Smith H, Jan M, Mahomed NN, Davey JR, Gandhi R. Meta-analysis and systematic review of clinical outcomes comparing mobile bearing and fixed bearing total knee arthroplasty. J Arthroplast. 2011;26(8):1205-13.

6. Kim YH, Kim JS, Choe JW, Kim HJ. Long-term comparison of fixed-bearing and mobile-bearing total knee replacements in patients younger than fiftyone years of age with osteoarthritis. J Bone Joint Surg Am. 2012:94(10):866-73.

7. Hofstede SN, Nouta KA, Jacobs W, van Hooff ML, Wymenga AB, Pijls BG, et al. Mobile bearing vs fixed bearing prostheses for posterior cruciate retaining total knee arthroplasty for postoperative functional status in patients with osteoarthritis and rheumatoid arthritis. Cochrane Database Syst Rev. 2015;2:CD003130.

8. Ranawat CS, Meftah M, Windsor EN, Ranawat AS. Cementless fixation in total knee arthroplasty: down the boulevard of broken dreams - affirms. J Bone Joint Surg Br. 2012;94(11 Suppl A):82-4.

9. Moskal JT, Capps SG. Rotating-platform TKA no different from fixed-bearing TKA regarding survivorship or performance: a meta-analysis. Clin Orthop Relat Res. 2014;472(7):2185-93.

10. Gandhi R, Tsvetkov D, Davey JR, Mahomed NN. Survival and clinical function of cemented and uncemented prostheses in total knee replacement: a meta-analysis. J Bone Joint Surg Br. 2009;91(7):889-95.

11. Drexler M, Dwyer T, Marmor M, Abolghasemian M, Sternheim A, Cameron HU. Cementless fixation in total knee arthroplasty: down the boulevard of broken dreams - opposes. J Bone Joint Surg Br. 2012; 94(11 Suppl A):85-9.

12. Yang $\mathrm{JH}$, Yoon $\mathrm{JR}$, Oh $\mathrm{CH}$, Kim TS. Hybrid component fixation in total knee arthroplasty: minimum of 10-year follow-up study. J Arthroplast. 2012;27(6): 1111-8.

13. Sharkey PF, Lichstein PM, Shen C, Tokarski AT, Parvizi J. Why are total knee arthroplasties failing today-has anything changed after 10 years? J Arthroplast. 2014;29(9):1774-8.

14. Sharkey PF, Hozack WJ, Rothman RH, Shastri S, Jacoby SM. Why are total knee arthroplasties failing today? Clin Orthop. 2002;404:7-13.

15. Gioe TJ, Killeen K, Grimm K, Mehle S, Scheltema K. Why are total knee replacements revised?: analysis of early revision in a community knee implant registry. Clin Orthop. 2004;428:100-6.

16. Fehring TK, Odum S, Griffin WL, Mason JB, Nadaud M. Early failures in total knee arthroplasty. Clin Orthop. 2001;392:315-8.

17. Nakama GY, Peccin MS, Almeida GJ, Lira Neto Ode A, Queiroz AA, Navarro $\mathrm{RD}$. Cemented, cementless or hybrid fixation options in total knee arthroplasty for osteoarthritis and other non-traumatic diseases. Cochrane Database Syst Rev. 2012;10:CD006193.

18. O'Brien S, Spence DJ, Ogonda LO, Beverland DE. LCS mobile bearing total knee arthroplasty without patellar resurfacing. Does the unresurfaced patella affect outcome? Survivorship at a minimum 10-year follow-up. Knee. 2012 19(4):335-8.

19. Waters TS, Bentley G. Patellar resurfacing in total knee arthroplasty: a prospective randomized study. J Bone Joint Surg Am. 2003;85(2):212-7.

20. Barrack RL, Wolfe MW, Waldman DA, Milicic M, Bertot AJ, Myers L. Resurfacing of the patella in total knee arthroplasty. A prospective randomized double-blind study. J Bone Joint Surg Am. 1997;79:1121-31.
21. Wood DJ, Smith AJ, Collopy D, White B, Brankov B, Bulsara MK. Patellar resurfacing in total knee arthroplasty: a prospective randomized study. Bone Joint Surg Am. 2002;84(2):187-93.

22. Burnett RS, Haydon $\mathrm{CM}$, Rorabeck $\mathrm{CH}$, Bourne RB. Patella resurfacing versus nonresurfacing in total knee arthroplasty. Clin Orthop Relat Res. 2004;428:12-25.

23. Smith AJ, Wood DJ, Li MG. Total knee replacement with and without patellar resurfacing: a prospective randomised trial using the Profix total knee system. J Bone Joint Surg (Br). 2008;90(1):43-9.

24. Matsuda S, Ishinishi T, Whiteside LA. Contact stresses with an unresurfaced patella in total knee arthroplasty. The effect of femoral component design. Orthopedics. 2000:23:213-8.

25. Chew JT, Stewart NJ, Hanssen AD, Luo ZP, Rand JA, An KN. Differences in patellar tracking and knee kinematics among three different total knee designs. Clin Orthop Relat Res. 1997;345:87-98.

26. Benjamin JB, Szivek JA, Hammond AS, Kubchandhani Z, Matthews AI Jr, Anderson P. Contact areas and pressures between native patellas and prosthetic femoral components. J Arthroplast. 1998;13:693-8.

27. He JY, Jiang LS, Dai LY. Is patellar resurfacing superior than nonresurfacing in total knee arthroplasty? A meta-analysis of randomized trials. Knee. 2011; 18(3):137-44.

28. Thompson NW, Ruiz AL, Breslin E, Beverland DE. Total knee arthroplasty without patellar resurfacing in isolated patellofemoral osteoarthritis. J Arthroplast. 2001;16(5):607-12.

29. Hamelynck KJ, Stiehl JB. Alternative technique of conservative distal femoral cut first. LCS mobile bearing knee arthroplasty 25 years of world wide experience. Revision total knee arthroplasty. New York: Springer; 2002. p. 183-94.

30. Thompson NW, McAlinden MG, Breslin E, Crone MD, Kernohan WG, Beverland DE. Periprosthetic tibial fractures after cementless low contact stress total knee arthroplasty. J Arthroplast. 2001;16(8):984-90.

31. Pagoti R, O'Brien S, Doran E, Beverland D. Unconstrained total knee arthroplasty in significant valgus deformity: a modified surgical technique to balance the knee and avoid instability. Knee Surg Sports Traumatol Arthrosc. 2017:25(9):2825-34.

32. Sperner G, Wantschek P, Benedetto KP, Glotzer W. Spatergebnisse bei Patellafrakturen. Akt Traumatol. 1990:20:24

33. Napier RJ, Bennett D, McConway J, Wilson R, Sykes AM, Doran E, O'Brien S, Beverland DE. The influence of immediate knee flexion on blood loss and other parameters following total knee arthroplasty. BJJ. 2014;96-B(2):201-9.

34. Cusick LA, Beverland DE. The incidence of fatal pulmonary embolism after primary hip and knee replacement in a consecutive series of 4253 patients. J Bone Joint Surg Br. 2009;91(5):645-8.

35. Ogonda L, Hill J, Doran E, Dennison J, Stevenson M, Beverland D. Aspirin for thromboprophylaxis following primary lower limb arthroplasty: early thromboembolic events and 90-day mortality in 11459 patients. Bone Joint 2016:98-B:341-8.

36. Arthroplasty Care Practitioners. Available at: http://www.acpa-uk.net. Accessed 27 Apr 2016

37. Ewald FC. The knee society total knee arthroplasty roentgenographic evaluation and scoring system. Clin Orthop Relat Res. 1989;248:9-12.

38. Thompson NW, Wilson DS, Cran GW, Beverland DE, Stiehl JB. Dislocation of the rotating platform after low contact stress total knee arthroplasty. Clin Orthop Relat Res. 2004;425:207-11.

39. No authors listed. National Joint Registry for England and Wales: 12th Annual report, 2014. http://www.njrcentre.org.uk.

40. No authors listed. Australian Orthopaedic Association national joint replacement registry. Annual Report 2015. https://aoanjrr.sahmri.com.

41. No authors listed. The Swedish Knee Arthroplasty Register: annual report, 2014. http://myknee.se/pdf/SKAR2014_Eng_1.1.pdf.

42. Rothwell A, Hobbs T, Frampton C. New Zealand Orthopaedic association: New Zealand joint registry: 16th year report January 1999 to December 2014. 2015. http://www.nzoa.org.nz/system/files/Web_DH7657 NZJR2014Report v4_12Nov15.pdf.

43. Hailer NP, Garellick G, Kärrholm J. Uncemented and cemented primary total hip arthroplasty in the Swedish hip arthroplasty register. Acta Orthop. 2010; 81(1):34-41

44. Park JW, Kim YH. Simultaneous cemented and cementless total knee replacement in the same patients: a prospective comparison of long-term outcomes using an identical design of NexGen prosthesis. J Bone Joint Surg [Br]. 2011;93-B:1479-86. 
45. Baker PN, Khaw FM, Kirk LM, Esler CN, Gregg PJ. A randomised controlled trial of cemented versus cementless press-fit condylar total knee replacement: 15-year survival analysis. J Bone Joint Surg [Br]. 2007;89-B:1608-14.

46. Lombardi AV Jr, Berasi CC, Berend KR. Evolution of tibial fixation in total knee arthroplasty. J Arthroplast. 2007;22(4 Suppl 1):25-9.

47. Harwin SF, Kester MA, Malkani AL, Manley MT. Excellent fixation achieved with cementless posteriorly stabilized total knee arthroplasty. J Arthroplast. 2013;28(1):7-13.

48. McEwen HM, Fisher J, Goldsmith AA, Auger DD, Hardaker C, Stone MH. Wear of fixed bearing and rotating platform mobile bearing knees subjected to high levels of internal and external tibial rotation. J Mater Sci Mater Med. 2001;12(10-12):1049-52.

49. Hopley CD, Crossett LS, Chen AF. Long-term clinical outcomes and survivorship after total knee arthroplasty using a rotating platform knee prosthesis: a meta-analysis. J Arthroplasty. 2013:28(1):68-77. e1-3

50. Carothers JT, Kim RH, Dennis DA, Southworth C. Mobile-bearing total knee arthroplasty: a meta-analysis. J Arthroplasty. 2011;26(4):537-42.

51. Tibrewal SB, Grant KA, Goodfellow JW. The radiolucent line beneath the tibial components of the Oxford meniscal knee. J Bone Joint Surg Br. 1984; 66(4):523e8.

52. Mukherjee K, Pandit H, Dodd CA, Ostlere S, Murray DW. The Oxford unicompartmental knee arthroplasty: a radiological perspective. Clin Radiol. 2008;63(10):1169-76

53. Gulati A, Chau R, Pandit HG, et al. The incidence of physiological radiolucency following Oxford unicompartmental knee replacement and its relationship to outcome. J Bone Joint Surg (Br). 2009:91-B:896-902.

54. Liddle AD, et al. Cementless fixation in Oxford unicompartmental knee replacement - a multicentre study of 1000 knees. BJJ. 2013;95-B(2):181-7.

55. Hozack WJ, Rothman RH, Booth RE Jr, Balderston RA. The patellar clunk syndrome. A complication of posterior stabilized total knee arthroplasty. Clin Orthop Relat Res. 1989;241:203-8.

56. Ma HM, Lu YC, Kwok TG, Ho FY, Huang CY, Huang CH. The effect of the design of the femoral component on the conformity of the patellofemoral joint in total knee replacement. J Bone Joint Surg (Br). 2007:89(3):408-12.

57. Medical Devices safety update. DEVICE CORRECTION NOTICE for the LCS

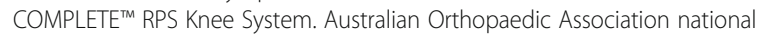
joint replacement registry. Annual Report 2015. https://www.tga.gov.au/ alert/lcs-complete-rps-knee-system-used-knee-replacements.

58. Pilling RW, Moulder E, Allgar V, Messner J, Sun Z, Mohsen A. Patellar resurfacing in primary total knee replacement: a meta-analysis. J Bone Joint Surg Am. 2012;94(24):2270-8.

59. Feng B, Weng X, Lin J, Jin J, Qian W, Wang W, Qiu G. Long term follow up of clinical outcome between patellar resurfacing and nonresurfacing in total knee arthroplasty: Chinese experience. Chin Med J. 2014;127(22):3845-51.

60. Mockford BJ, Beverland DE. Secondary resurfacing of the patella in mobilebearing total knee arthroplasty. J Arthroplast. 2005;20(7):898-902.

\section{Ready to submit your research? Choose BMC and benefit from:}

- fast, convenient online submission

- thorough peer review by experienced researchers in your field

- rapid publication on acceptance

- support for research data, including large and complex data types

- gold Open Access which fosters wider collaboration and increased citations - maximum visibility for your research: over $100 \mathrm{M}$ website views per year

At BMC, research is always in progress.

Learn more biomedcentral.com/submissions 